\title{
ALTERNATIVE SERVICES - NEW SERVICE FOR EVERY CHILD
}

\author{
Denada Seferi (Dibra) \\ $\mathrm{PhD}$ Cand. \\ Ministry of Social Welfare \&Youth \\ de.dibra@yahoo.it \\ Etleva Zeqo (Murati) \\ PhD Cand. \\ Parliament of Albania \\ etlevaz@yahoo.com \\ Tirana-Albania
}

DOI:10.5901/mjss.2014.v5n19p286

\begin{abstract}
Every child, for a full and harmonious development of his/her personality, has the right to grow up in a family environment, in an atmosphere of happiness, love and understanding1. This principle is one of the main pillars of foster care service. In Albania,familyfoster careservice is one of the new forms of social services as an indicator of taken responsibilities by the wellfare state to protect children including children with disabilities, who are deprived of parental care. Foster Care, or as it is called in Albanian Family Code "foster family", is a form of alternative care for children who are not provided with family care by their families. Throughout human history, there are constantly encountered phenomenas of neglect, abuse, intentional murder, sale and abandoning children mainly from ptheir parents. Foster care service was firstly a spontaneous response and then anoficial one, to support children who were vulnerable and deprived of family care. The models of providing foster care services are different from temporary service, the emergency ones, or long-term, and specialized ones. Currently, the Court is the only institution that takes decisions for child guardianship, for his accomodation in asocial care institution or in an alternative family. Basic international obligations in the field of protection of children deprived of parental care are setby the Convention on the Rights of the Child (CRC). Albania became party in the CRC on March 281992 and in its Optional Protocols "On the involvement of children in armed conflicts" and "On sale of children, child prostitution and child pornography" 2 in 2007, these acts being in accordance with the constitutional provisions are now part of the Albanian legal system 3. In Albania foster care is a special service offered as protection measure for juvenile in the conditions when their parents are unable to exercise their parental responsibility. The reason for this can be the situations when both parents have died or are not known, are declared missing, lack the legal capacity to act, poverty and for any other reason accepted by the court. The goal is that the child be offered a family environment and conditions for the upbringing, such as physical care and emotional support. Such an alternative service was adopted in Albania as a new form of service to improve and increase the efficiency of the delivery of social services in addition to services in social care institutions 4, which provide basic services for each juvenile. By reforming the Social Protection program5, the Albanian government had two priorities: Prevention of institutionalization of children and the provision of services in a family environment. This service is being extended throughout Albania creating the appropriate environment to treat the children in new forms of care as closed as possible to the family. The state is leading this service supporting it as an alternative to institutionalization to guaranty child upbringing.
\end{abstract}

Keywords: family foster care services; children with disabilities; alternative family; poverty; prevention of institutionalization.

${ }^{1}$ Article 5 , Family Code of Albania

2Law no. 9893, dated 22.11.2007 \& Law no. 9894, dated22.11.2007 "On the accession of CRC Optional Protocols

${ }^{3}$ Article 116, of the Albanian Constitution

${ }^{4}$ Social care institutions - institutions providing basic services, 19 public institutions allover the country

${ }^{5}$ Social Care Reform - initiated by UNICEF in 2010 (First Conference on Social Care Reform) 


\section{Historical context of the development of foster care}

Throughout human history phenomena of neglect, abuse, intentional murder , child abandonment and sales mainly from parents who were unable to raise and care for them are constantly encountered.

"Bosëell", a known sociologist has made us familiar with the fact that the response to this situation gave birth to the phenomenon of care to these children , called " kindness of strangers " who rescue these children growing them up as they were theirs. It was a spontaneous and unofficial response to support vulnerable children deprived of family care .

Over time there were created and developed different systems of foster care in different countries of the world in response to this phenomenon .

The common trend linking the developments in these countries was the gradual evolution from an informal system to a formal system of foster care for these children regardless of the pace of this which development varied from country to country. A slightly more formal way appeared in Germany around the 11th and 12th centuries. This form is applied mainly from wealthy families based on a private agreement, in cases where they were looking for care opportunities for their children during a certain period of time .

The families where these children could be resettled were families of their relatives or not.

The term widely used at that time for these children was " Alumni " , a term that is currently used for graduate students . Evolution Stages of foster care services:

\section{1. " Poor law"}

( poor law) as the spark of the first beginnings of foster care;

\section{2 . Accommodating latant children at homes of healthy wet nurses;}

3 . Long-term foster care as a replacing form of parental care ;

4. The custody, a form of temporary foster care;

5 . The professionalisation of foster care ;

\section{Methodology .}

The article includes : i) Institutional Assessment, ii ) legal assessment Studying of materials, National decentralization strategy and national social protection strategies ; Analysis of the institutional framework regarding functioning of social services in Albania , structures and responsibilities ;

Analysis of issues related to the implementation of programs over the years, debates on the policy-making level, in the annual analysis, on drafting strategies at national level etc.

\section{Content}

For a full and harmonious development of personality, every child has the right to grow up in a family environment, in an atmosphere of happiness, love and understanding. This principle is one of the main pillars of domestic foster care services

In Albania , family foster care services is one of the new forms of social services as a reflection of taken responsibilities from the state to protect children who are deprived of parental care .

" Family foster care," is a form of alternative care for children who are outside the parental care.

Family foster care is often used to provide temporary care while parents are assisted to resolve their problems, or to help children or young people which are in a difficult period of their lives .

children Often will return home as soon as the problem that has brought them in a foster family setting is solved and it has become clear that parents can appropriately exercise their parental responsibility .

Others can stay in a foster family, some may be adopted and some others will later continue to have an independent life.

Convention on the Rights of the Child sets Basic international obligations in the field of protection of children deprived of parental care ( CRC ). 
Albania became party to the CRC on March 28, 1992 and of its Optional Protocols "on the involvement of children in armed conflicts " " For sale of children, child prostitution and child pornography" in 2007 , acts which in accordance with the constitutional provisions are now part of the Albanian legal system. The Constitution recognizes the legal validity of the ratified international traeties and agreements, only after their publication in the Official Journal , and the principle of their self-aplicability , excluding those provisions which do not have direct effect and their application requires the adoption of the new laws.

The Constitution guarantees the priority of the CRC above domestic law, as long as the this one is inconsistent with its provisions . CRC text in Albanian can be found online on the official website of the Ministry of Labour Social Affairs and Equal Opportunities .

According the Albanian constitution, children enjoy special protection from violence, abuse, exploitation, use for work , protection of their health , moral or normal development .

Article 20 of the $\mathrm{CRC}$ is one of the specific articles regarding alternative care of children in foster families .

It provides that a child deprived temporarily or permanently of his family environment, or when it is not in his highist interest to stay in this environment, is entitled to have protection and assistance provided by the state .

States Parties shall ensure to this child an alternative care, in accordance with their domestic legislation .

Such an alternative foster care could include, inter alia , the form of a family setting , the "Kafala " according to Islamic law, adoption or if necessary placement in a suitable child care -giving centers.

When solutions are to be found, the desirability for continuity in a child's education, as well as his , ethnic, religious , cultural and linguistic origin should be kept in mind.

Children can be temporarily or permanently deprived of their family life, or because of circumstances such as death , abandonment, or replacement, or because the state decides that the child should be removed from parental care in their highist interest

So foster care service is one of the ways of " special protection and assistance ", which all the children who are deprived of family care have the right to enjoy.

Children from deprived families often have greater needs than simply alternative accomodation.

Loss of the family relations and that of the identity along with instability and difficulties of a new accomodation may hinder their emotional , physical and intellectual development.

Committee on the Rights of the Child explicitely declares that the special protection provided to children deprived of family care should include the child's accomodation preference with a suitable family, including members of their families or where appropriate at families with children, families and caregivers or adoptive families, these families should be given the necessary support and supervision ; and temporary placements should be monitored and reviewed regularly .

Guidelines for the Alternative Care of Children ( Guidelines ) represent the most detailed instrument of international law in the field of alternative care for children outside of parental care .

Family foster care is a form of alternative care for these children, which regulates provisions governing the foster care service and family foster care one.

General provisions are applicable to all forms of alternative foster care, including family foster care services, while they only apply to this particular service.

They are applied to alternative care for persons under 18 years old, or age of maturity is reached earlier .

Only when it is specifically declared, the Guidelines also are applied in cases of informal foster care bearing in mind the role played by extended families, communities and the obligations that state has towards all children outside of parental care or legal custody, as provided in the CRC. The principles of these guidelines are also applied to young people who are in alternative care and who need constant care and support for a transitional period until they reach maturity age defined by law . These Guidelines although considered soft ( soft law ), thus not obligatory to be applied, represent a fundamental development in setting standards regarding alternative care for children outside of parental care .

The resolution sents minimum standards . 
It is clearly said by the Article 26 thereof, which means that States may set higher standards than those provided in the Guidelines .

So Guidelines represent the least common denominator in terms of international standards in this field .

Their aim is to improve the implementation of the CRC and other provisions for the protection and welfare of the child deprived of parental care, or who is at risk of being out of this care .

The guidelines establish desirable orientations for policy-making and practice .

In particular, they require :

(a) to support efforts to maintain or to return children into the care of family , or find another suitable and permanent form, including adoption; if this is impossible ;

( b ) to ensure that while these permanent solutions are required, or if they are impossible or are not in the best interests of the child, the most appropriate forms of alternative care be identified and provided under conditions that promote the full development and harmonious child ;

To direct the policies , decisions and actions of all actors working on social protection and welfare of children in public and private sectors, including civil society .

\section{Socio-economic situation}

Albania's economy in the last 15 years has noted steady economic growth .

Albania remains one of the poorest countries in Europe, with 4257 USD per capita and high disparities between different areas and social groups .

Economic growth, social policies and programs, remittances from emigrants and other socioeconomic factors, have contributed to reduce poverty and increase the quality of life of groups and individuals in need .

Currently , $14.3 \%$ of the population is estimated to be under the absolute poverty line or to have less than 2 USD per day per capita . This proves that children belonging to this social group , face poverty, malnutrition, lack of education, health care etc. In these conditions, children face wiht two major problems that lead to social exclusion and denial of their basic rights :

(i) socio - economic, social, geographical and cultural inequality.

Improvements noticed in the macro level until now , are focused mainly in Tirana and in the main cities and suburban areas , especially northeast or some communities such as the Roma and Egyptians etc experience greater difficulties.

(ii ) insufficient and inability to use qualititive social services in accordance with their needs, because they lack preventive and integrating services, or the income in their families .

Social exclusion of a part of children is a consequence of the level and depth of poverty, unequal distribution of income between different areas and social groups, new commers from immigration and other factors .

Albania, with a population of 2,831,7411million inhabitants, has one of the youngest populations in Europe, while the number of children aged 0-19 years is about 1,000,000. Albania has had and continues to be engaged with regard to the improvement of standards for the protection and respect of basic human rights.

Phenomena like transition, change of system and of the family model from a large one to a small one have led to a weak social traditional and child care links.

Child protection is part of social protection. More specifically, it has to do with prevention and response to "all forms of physical or mental violence, abuse or ill-treatment, abandonment or neglect or exploitation, including sexual abuse of children", as provided for by article 19 of the UN Convention of the Rights of the Child.

1 INSTAT, Population and housing, census in Albania, preliminary results, 2011. 
Currently, residential care is given to 0-16 year-old children, 265 children in public residential centers and 400 in non-public residential centers. The number of children aged 0-3 years in public institutions is 99 , whereas in non-public institutions is 55.

The Albanian Government has approved the Foster Care Strategy for children in need in 2008, which constitutes an important document and promotes new alternative home-based services for the children in need.

Foster care service is based in the decentralization of services, deinstitutionalization of children and establishing of community services, where a child is being supported and assisted in a family environment and his/her basic rights that derive from the UNCRC are guaranteed at the highest level. It is estimated that alternative care is less expensive than residential care (the cost of one child under 3 years old in the institutions is 73,000 Leke, about 700 usd) 1 thus constituting a strong argument for promoting such services.

The phenomenon of the exclusion of children is recognized too little and the existing system of social protection is not oriented towards providing for the groups of excluded children .

Some of the groups of children in critical economic and social situation, which rights are denied or not respected are :

Children of the poorest families, who live with economic assisstence , are more at risk of social exclusion , multiple social disadvantages as difficulties in obtaining basic services such as education , health , housing and social protection .

It is estimated that about 160,000, children living in poor families receiving economic aid, the main source of living which is economic aid.

Children who lack parental care : according to the State Social Service for 2013 in the formal system are 1,198 registered children outside of parental care ; about 448 of them are located in public institutions ( 350 in institutions for children aged 0-3, 3-6 and 6-14 are in children's homes(orphanages) and 98 children in residential centers for the development of children with disabilities ) .

The rest is under the auspices of non -profit organizations, ( 581 children were placed in small residential centers or day centers , 169 children are in the family and each year about 60 children are adopted domestically and abroad.

An analysis of datas on the number of children placed in institutions as well as the dynamics of entring and getting out from these institutions, shows that approximately $70 \%$ of the children come from poor families or families with social problems , $25 \%$ of them are abandonedsince birth and $5 \%$ of them are accomodated in institutions for other reasons, including the repatriation of trafficked children and child workers.

Children with disabilities : are recognized From administrative system of datas only in the number of children who receive disability payments for mental, physical, visual or hearing impairment.

There are around 30,000 children who receive disability payments from 124,000 treated in country level. Approximately 60 $\%$ of children with disabilities live in rural areas .

Based on the world experiences, Albania in addition to care services provided in public and private residential institutions, in 2009 aproved the legislation that provides foster care services for children in the families of other so-called family carers.

In this service not only children without parental care are placed but also those children who have a heavy social and economic situation from different factor such as poverty, violence, who can not have the care of family members .

Promoting foster care service as an alternative to new domestic services is based on the decentralization and deinstitutionalization process, and increasing new services, where the child is supported and assisted in a family environment .

The state provides financial support for expenses such as food, clothing , school and other indirect costs for A child placed in foster family.

Greater support is offered when a child with disability is placed in foster families.

Foster care is a special service that offers protection for children when their parents are unable to exercise the parental responsibility .

1 Prepare an assessment on the costing of protection services in Albania, UNICEF \&MOLSAEO 2011. 
The reason for this can be the situation when both parents have died or are not known, are missing , are deprived of the ability to act and for any other reason accepted by the court .

Despite the adoption of administrative tender procedure , legislation recognizes the court again as the only institution to decide child custody, for his foster care in an institution or in an alternative family .

The purpose of placing the child is that he be offered a family environment and conditions for the upbringing , physical care and emotional support .

Custody as an alternative social service for children at risk should provide :

- continuity of child up-bringing in a family environment through a replacing family where the child feels surrounded by family attention and care .

- attention to development in accordance with the age, the child's individual needs and service standards custody .

- socialization and reintegration of the child with the biological family, relatives, adoptive family and / or community .

- Monitoring of the child during his stay in the foster family .

Foster care Service is realized by respecting the fundamental principles in the interest of the child :

- the right of the child to be grown up in a family environment in accordance with the age, child's needs, and the standarts of foster care service;

- the identity of the child ;

- maintaining relationships with the biological family of the child;

- placement of other siblings in the same foster family;

- respecting the opinion of the child ;

- avoiding the discrimination ;

- offering multidisciplinary service to him ;

- Individual interventions appropriate for each child ;

- access to high quality services in accordance with agreed standards .

The term of the foster care is determined depending on the specifications and needs of each case .

Foster care is considered short when the foster family residence does not exceed 12 months .

Foster care is considered long when staying in foster family takes more than months, until the child reaches the age of maturity, 18 years. Foster care is implemented in emergency situations the child .

In this case the child's emergency replacement is made in accordance with the legal procedures followed regarding custody aiming to respect minimum terms set by the Court ( pursuant to Section 281 and 300 of the Family Code : Urgent measures ).

This form of foster care applies when it is valuated as the best alternative in order to protect the best interest of the child by the aturny and the respective employees who have identified the problems .

Several public institutions and other private operators who provide information for cases in need and commit to providing accommodation and foster care services are included for placement of the child in custody.

So this kind of service is decentralized and it involves providing foster care service institutions such as the Office of Social Services of the Municipality / Municipality ; NGOs licensed / contracted to provide services for children and families, the district court where the child resides, Social Services Inspectorate, Ministry of Social Welfare and Youth .

These institutions assess :

- All cases in need of foster care services and families who show interest are included as foster family;

- information regarding the child, the biological family, and potential foster family ; 
- fulfilling the criterias set for the selection of foster families and providing opportunities of this service ;

- training of foster families for this service ;

- preparation of the necessary documentation for children and foster family;

and provide recommendations on the selection of a foster family ;

As foster care services are implemented: The foster care service for a 2 -year period was funded by UNICEF ...

The professionalisation of foster care ;

Not so logn ago foster care is seen as a service for children " normal / healthy / no problematic " .

Only in 1970 it began to be talked to a professional foster care, care-giver or specialized treatment setup by creating the opportunity to extend the range of foster care services to children with special needs such as physiological , cognitive , psychological , emotional, social, behavioral, etc.

Initially foster care was used to remove the teens who were in conflict with the law while currently lies and serves to all children with the most varied.

Key concepts that permeate this foster care service " are normalization of life of the child ", " community service " and " treatment" .

Normalization of the child's life emphasizes the right of each individual, including children to have a normal life in the community .

The main purpose of foster care service is to provide specialized care and treatment and not just care.

Treatment implies the idea of a proactive attitude to help a child manages problem solving and faces difficult emotional , behavioral or other .

This service should be planned with more details, oriented activities clear goals, clear expectations and methodology.

Foster families that provide this kind of care should have a certain set of skills to cope with various problems.

For this reason, more and more the spectrum of foster family recruitment criterias is increasing.

Individuals with certain qualities are invited to apply for a particular job where financial reward is necessary as a reward .

Specialized programs are spread across the world and continuesly evolve and improve more and more every day.

\section{RECOMANDATION AND CONCLUSIONS}

The experiences in developing Foster Care as a cost effective alternative to institutional care whilst at the same time improving outcomes for vulnerable children and young people, is very important in Albania. Based on the experience in Northern Ireland about foster care, which was of particular interest 1in regard to how this was achieved, we propose various experiences and policies relating to the following:

Developing a scheme for foster care focussing on the key types of foster care including;

long-term foster parents

short-term foster parents

respite foster parents

emergency foster parents

pre-adoption foster parents

special needs foster parents.

1 Paul Martin- Nico study 
Assessment of foster parents in relation to their suitability to foster children with different needs

Assessment of children in State care or at risk in determining the appropriateness of foster care for them

Recruitment and retention of foster parents

Training of foster parents in preparation for fostering

Ongoing professional support for foster parents

Financing a foster care service, including the costs of extending foster care to 23 years of age thereby achieving more positive outcomes for vulnerable young adults.

\section{Developing Social Work as a Profession}

It is in high importance to have in place competent and confident professional social workers identified as vitally important in securing the objectives of the reform program. Given the UK experience over the last 3 decades it may be helpful to share this experience in reforming this part of their workforce.

It is very sought to define clearly the roles, tasks and responsibilities which social workers undertake, thereafter deciding on the education and training social workers which would require to enable them to undertake these various roles. Following this, reaching agreement with Universities and further education colleges on how best future training and education should be delivered to social work professionals both at undergraduate and post-graduate levels and building in a programme for continuous professional development.

We considered the usefulness of social work strategy and the codes of practice to bring clarity to the social workers and social care workers as to what is expected of them and importantly what people using social care services can expect from social workers.

We would suggest :

The Family Support Strategy as a set for family services as a Government's top priorities in the social care sector;

Sure start programmes for family support introduced some years ago, have also much to commend them given the current position in Albania and the focus on developing local responses to supporting vulnerable families and children.

Positive Parenting programmes, which focus on building on the existing strengths of parents and giving greater confidence and parenting skills to parents at risk of abandoning or abusing their children, would also be of some assistance

Developing new Family Centres and reforming existing centres is also an area that has seen significant improvement. This experience may be helpful to those charged with this responsibility in Albania for this service. It maybe helpful to share new therapies aimed at helping parents to improve their parenting skills, using music and art therapies, personal story books, family trees etc all of which have a part to play in an effective family centre service to vulnerable parents and children.

Finally, respite care services for parents who are struggling to manage their children, can be developed in Albania.

\section{References}

Law no. 8417, dated 12.21.1998, "The Constitution of the Republic of Albania" Law no. 9893, and Law No. Date 22.11.2007. 9894, Date 22.11.2007 for adhering to the Optional Protocols to the CRC Law No. 9062, dated "Family Code" Law No. 9355 dated 10.03.2005 "On Social Assistance and Social Services" changed Law no. 9695 dated 19.03.2007 "On the procedure of adoption of the child and the Albanian Committee of Adoption DCM nr.658 dated 17.10.2005, the standards of " DCM nr.659 dated 17.10.2005 "On standards of social care services for children in residential institutions" DCM No. 822, dated 06.12 .2006 on "standards of social care services for people with disabilities in residential and day centers"

DCM no. 195 dated 11.04.2007 "On approval of social care standards in residential centers for trafficked persons or persons at 


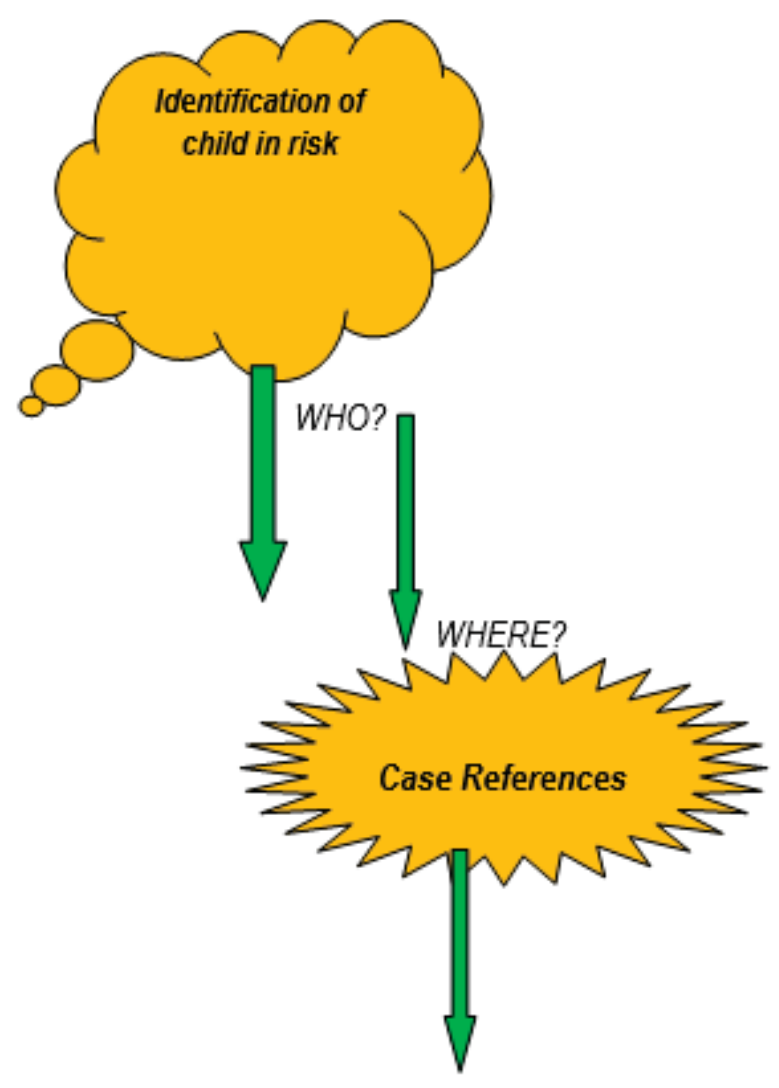

Identificat
ion of
case
manager
Evaluatio
$n$
psikosoci
al of child
and
his/her
family
biologijike
Determ
ination of
occasional
reference to
appropriate
services under
provided undion
child protection
Having in
consideration
the placement
of the child
infoster care
family

Child evaluation and his/her biological family

Evaluation of parents (as a potential foster care family. Evaluation of child and his/her family who will be as a potential family foster care, based on evaluation of multidisciplinary equipe.
Vendimi $i$ Gjykates per vendosjen ne kujdestari 